\title{
Effect of Fenofibrate on Uric Acid Metabolism in Japanese Hyperlipidemic Patients
}

\author{
Yoshihiko Noguchi, Ichiro Tatsuno, Keiko Suyama, Takahisa Shibata, Tomohiko Yoshida, \\ Yuko Otsuka, Masami Fuse, Chikari Takeo, and Yasushi Saito
}

The department of Clinical Cell Biology, Chiba University Graduate School of Medicine

\begin{abstract}
Forty Type IIb or IV hyperlipidemic patients (serum triglyceride concentrations were higher than $150 \mathrm{mg} / \mathrm{dl})$ were treated with fenofibrate $(300 \mathrm{mg} / \mathrm{day})$ for 12 weeks. Lipid profile and uric acid metabolism were evaluated before and after the treatment; the serum concentrations of total cholesterol and triglyceride respectively decreased from $224 \pm 41.9 \mathrm{mg} / \mathrm{dl}$ to $199 \pm 35.2 \mathrm{mg} / \mathrm{dl}$ and from $205 \pm 71.7 \mathrm{mg} / \mathrm{dl}$ to $134 \pm 67.5 \mathrm{mg} / \mathrm{dl}(p<$ 0.001 ). The uric acid concentrations in the serum also significantly decreased from $7.0 \pm 1.58 \mathrm{mg} / \mathrm{dl}$ to $5.2 \pm 1.57 \mathrm{mg} / \mathrm{dl}(p<0.001)$. Fenofibrate treatment did not cause any change in the serum xanthine and hypoxanthine concentrations. Instead the urinary concentrations of uric acid decreased from $7.0 \pm 1.58 \mathrm{mg} / \mathrm{dl}$ to $5.2 \pm 1.57 \mathrm{mg} / \mathrm{dl}(p$ $<0.01$ ), while the clearance ratio of uric acid and creatinin increased from $6.1 \pm 2.56$ to $9.9 \pm 3.87(p=0.02)$ by the fenofibrate treatment. Fenofibrate decreases uric acid concentrations in the serum not as a result of inhibition of uric acid production but by increasing the urinary excretion of uric acid. J Atheroscler Thromb, 2004; 11: 335-340.
\end{abstract}

Key words: Fenofibrate, Uricosuric action, Metabolic syndrome

\section{Introduction}

Hyperuricemia is a common condition in Japan (1). Patients with hyperuricemia have been increasing for several decades in Japan and it is thought that the increase is closely related to the change of life style in Japan (2, 3). Recently hyperuricemia has been considered as one component of multiple-risk factor syndromes, especially the visceral fat and the serum triglyceride concentrations are closely correlated to the serum uric acid concentrations (4-7). Analogous conditions to multiple-risk factor syndromes such as Syndrome X, visceral fat syndrome, and the deadly quartet are now termed "metabolic syndrome" (8). It is not clear whether hyperuricemia is one of the independent risk factors and the reduction of serum uric acid concentrations improves the prognosis of

Address for correspondence: Yoshihiko Noguchi, Department of Cellular Biology, Chiba University Graduate School of Medicine, 1-8-1 Inohana, Chuo-ku, Chiba 260-8670, Japan.

E-mail: yossy@graduate.chiba-u.jp

Received February 27, 2004.

Accepted for publication July 21, 2004. patients with metabolic syndromes. The serum uric acid level is, however, at a good indicator of severity and prognosis of such patients with metabolic syndromes (9-13). Patients with hyperuricemia caused by metabolic syndrome have a large number of metabolic abnormalities and need several kinds of medicines if they attempt to treat each problem independently. Recently it has been reported that fenofibrate, one of the fibrates, has the effects that are observed in the fibrate class agents and the anti-hyperuricemic effect (14-16). Some authors report that the anti-hyperuricemic effect of fenofibrate comes from its uricosuric action (17). There are several reports on the anti-hyperuricemic effect of fenofibrate as mentioned above, and the reports are focused on the hyperuricemic patients or healthy volunteers. This time, we have evaluated the anti-hyperuricemic effect of fenofibrate on patients with hyperlipidemia in the outpatient situations. Also we have considered the mechanism of the hyperuricemic effect of fenofibrate through the evaluation in the change of metabolism and excretion of uric acid by the treatment. 


\section{Subjects and Methods}

\section{Subjects and study design}

Forty cases of Type IIb or IV hyperlipidemic patients whose serum triglyceride concentrations were higher than $150 \mathrm{mg} / \mathrm{dl}$ were enrolled for this study from outpatients of the Second Department of Chiba University Hospital (all cases). The patients were fasted for $12 \mathrm{~h}$ before collecting the samples of blood and urine. Eighteen cases of hyperuricemic patients having uric acid concentrations higher than $7.0 \mathrm{mg} / \mathrm{dl}$ out of the forty cases were evaluated separately (hyperuricemic group). Patient profiles are shown in Table1.

Fenofibrate was given orally, a once daily dose of 300 $\mathrm{mg}$ in the morning for 12 weeks after the collection of the initial blood and urine samples before noon. At the 12th week of the repeated administration, the blood and urine samples were collected in the same way. Any drugs that had been given before the evaluation were to be continuously administered until this study finished. The same type and levels of diet and exercise continued until the end of the study. No case dropped out because of any side effects.

Items to be measured in this study were as follows: serum concentrations of total-cholesterol (T-Cho), triglyceride (TG), HDL-cholesterol (HDL-C), uric acid (UA), xanthine, and hypoxanthine, urinary concentrations of creatinin and UA. The uric acid clearance/ creatinin clear- ance ratio $(\mathrm{CUA} / \mathrm{Ccr}=R)$ was calculated from serum and urine UA and creatinin levels.

\section{Statistics}

The lipid profiles and uric acid metabolic markers were compared before and after the Fenofibrate treatment by student- $t$ test using Statcel software (OMS, Tokorozawa, Japan). $p$ values less than 0.05 were regarded as significant.

\section{Results}

\section{Effects of fenofibrate on lipid profile}

As previously described the 12-week fenofibrate treatment decreased the T-Cho and TG level with statistical significance. Changes of the lipid profiles after the fenofibrate treatment are shown in Table 2. There is no difference of lipid profile response to fenofibrate between male gender and female gender (data not shown). The body weight and other physical conditions were not changed by the treatment (data not shown). In the case of hyperuricemia, the same result was observed (Table. 2).

\section{Effects of fenofibrate on serum UA level}

The uric acid level decreased from $7.0 \pm 1.58 \mathrm{mg} / \mathrm{dl}$ to $5.2 \pm 1.57 \mathrm{mg} / \mathrm{dl}(p<0.0001)$ in all the cases. In the hyperuricemic group the uric acid level decreased from

Table 1. Clinical characteristics of patients.

\begin{tabular}{|c|c|c|c|c|c|c|c|}
\hline \multirow{2}{*}{\multicolumn{4}{|c|}{ All cases $(n=40)$}} & \multirow{2}{*}{\multicolumn{4}{|c|}{ Male gender $(n=24)$}} \\
\hline & & & & & & & \\
\hline Age & year & $56.9 \pm 12.40$ & & Age & year & $56.2 \pm 13.2$ & \\
\hline Gender & $\mathrm{M} / \mathrm{F}$ & $24 / 16$ & & T-cho & $\mathrm{mg} / \mathrm{dl}$ & $220 \pm 45.9$ & $(134-304)$ \\
\hline T-cho & $\mathrm{mg} / \mathrm{dl}$ & $224 \pm 41.9$ & $(134-304)$ & TG & $\mathrm{mg} / \mathrm{dl}$ & $219 \pm 114.2$ & $(152-494)$ \\
\hline $\mathrm{TG}$ & $\mathrm{mg} / \mathrm{dl}$ & $205 \pm 71.7$ & $(152-494)$ & HDL-C & $\mathrm{mg} / \mathrm{dl}$ & $53.8 \pm 19.56$ & $(21-81)$ \\
\hline HDL-C & $\mathrm{mg} / \mathrm{dl}$ & $55 \pm 16.1$ & $(21-81)$ & Uric acid & $\mathrm{mg} / \mathrm{dl}$ & $7.1 \pm 1.62$ & $(3.2-10.4)$ \\
\hline Uric acid & $\mathrm{mg} / \mathrm{dl}$ & $7.0 \pm 1.58$ & $(3.2-10.4)$ & CUA/Ccr $(R)$ & $\mathrm{mg} / \mathrm{dl}$ & $6.3 \pm 2.92$ & $(2.1-9.1)$ \\
\hline $\mathrm{CUA} / \mathrm{Ccr}(R)$ & $\mathrm{mg} / \mathrm{dl}$ & $6.2 \pm 2.58$ & $(2.1-9.1)$ & & & & \\
\hline \multicolumn{4}{|c|}{ Hyperuricemic group (UA > $7.0 \mathrm{mg} / \mathrm{dl}, n=18$ ) } & \multicolumn{4}{|c|}{ Female gender $(n=16)$} \\
\hline Age & year & $53.9 \pm 11.32$ & & Age & year & $57.9 \pm 10.6$ & \\
\hline Gender & $\mathrm{M} / \mathrm{F}$ & $14 / 4$ & & T-cho & $\mathrm{mg} / \mathrm{dl}$ & $231 \pm 35.7$ & $(162-290)$ \\
\hline T-cho & $\mathrm{mg} / \mathrm{dl}$ & $216 \pm 39.4$ & $(134-304)$ & TG & $\mathrm{mg} / \mathrm{dl}$ & $183 \pm 51.2$ & $(158-243)$ \\
\hline $\mathrm{TG}$ & $\mathrm{mg} / \mathrm{dl}$ & $224 \pm 92.7$ & $(152-494)$ & HDL-C & $\mathrm{mg} / \mathrm{dl}$ & $56.7 \pm 13.8$ & $(39-76)$ \\
\hline HDL-C & $\mathrm{mg} / \mathrm{dl}$ & $52 \pm 18.4$ & $(21-78)$ & Uric acid & $\mathrm{mg} / \mathrm{dl}$ & $6.9 \pm 1.61$ & $(4.1-9.4)$ \\
\hline Uric acid & $\mathrm{mg} / \mathrm{dl}$ & $8.0 \pm 0.96$ & $(7.2-10.4)$ & CUA/Ccr $(R)$ & $\mathrm{mg} / \mathrm{dl}$ & $6.1 \pm 1.87$ & $(4.5-9.1)$ \\
\hline CUA/Ccr $(R)$ & $\mathrm{mg} / \mathrm{dl}$ & $5.4 \pm 1.97$ & $(2.1-9.1)$ & & & & \\
\hline
\end{tabular}


$8.0 \pm 0.96 \mathrm{mg} / \mathrm{dl}$ to $5.9 \pm 1.48 \mathrm{mg} / \mathrm{dl}(p<0.001)$. For the purpose of clarifying that the effect of fenofibrate on uric acid level is attributed to the decrease of uric acid synthesis or increase in uric acid excretion, the xanthine and hypoxanthine levels and uric acid clearance/creatinin clearance ratio $(\mathrm{CUA} / \mathrm{Ccr}=R$ ) were measured before and after the treatment. $R$ was increased both in the all cases and the hyperuricemic group with statistical significance after treatment. The fenofibrate treatment did not cause statistically significant change in xanthine and hypoxanthine levels. There is no difference of fenofibrate effect on uric acid metabolism between male gender and female gender (Table.3).

\section{Discussion}

Fibrates belong to the antihyperlipidemic agents that reduce a plasma lipid concentration, especially TG (18, 19). The agents act as a PPAR alpha agonist to reduce a lipid concentration, change a lipid profile to anti-atherogenic state, increase an HDL-c concentration, and improve insulin sensitivity (20-23). Fibrates have been

Table 2. Effects of fenofibrate on lipid profile.

\begin{tabular}{lccccc}
\hline All cases & & \multicolumn{1}{c}{ Before } & After & $\%$ of change & $p$ value \\
\hline T-cho & $\mathrm{mg} / \mathrm{dl}$ & $224 \pm 41.9$ & $199 \pm 35.2$ & $-11 \%$ & $p<0.001$ \\
TG & $\mathrm{mg} / \mathrm{dl}$ & $205 \pm 71.7$ & $134 \pm 67.5$ & $-34 \%$ & $p<0.001$ \\
HDL-c & $\mathrm{mg} / \mathrm{dl}$ & $55 \pm 16.1$ & $63 \pm 19.2$ & $+14 \%$ & $p<0.001$ \\
LDL-c & $\mathrm{mg} / \mathrm{dl}$ & $113.9 \pm 46.4$ & $100.7 \pm 43.2$ & $-12 \%$ & $\mathrm{NS}$ \\
\hline Hyperuricemic group & $\mathrm{mg} / \mathrm{dl}$ & $215 \pm 44.1$ & $197 \pm 42.1$ & $-8 \%$ & $p<0.001$ \\
\hline T-cho & $\mathrm{mg} / \mathrm{dl}$ & $223 \pm 102.8$ & $165 \pm 105.6$ & $-23 \%$ & $p<0.001$ \\
TG & $\mathrm{mg} / \mathrm{dl}$ & $52 \pm 18.4$ & $61 \pm 19.2$ & $+17 \%$ & $p=0.004$ \\
HDL-c & $\mathrm{mg} / \mathrm{dl}$ & $96 \pm 22.4$ & $93 \pm 31.2$ & $-3 \%$ & $\mathrm{NS}$ \\
LDL-c & & & & $p$ of change \\
\hline
\end{tabular}

Table 3. Effects of fenofibrate on uric acid metabolism.

\begin{tabular}{|c|c|c|c|c|c|}
\hline All cases & & Before & After & $\%$ of change & $p$ value \\
\hline Uric acid & $\mathrm{mg} / \mathrm{dl}$ & $7.0 \pm 1.58$ & $5.2 \pm 1.57$ & $-25 \%$ & $p<0.01$ \\
\hline CUAVCcr $(R)$ & $\mathrm{mg} / \mathrm{dl}$ & $6.1 \pm 2.56$ & $9.9 \pm 3.78$ & $+62 \%$ & $p=0.02$ \\
\hline Xanthine & $\mu \mathrm{g} / \mathrm{dl}$ & $0.20 \pm 0.057$ & $0.16 \pm 0.022$ & $-0.8 \%$ & NS \\
\hline Hypoxanthine & $\mu \mathrm{g} / \mathrm{dl}$ & $0.52 \pm 0.236$ & $0.47 \pm 0.317$ & $-9 \%$ & NS \\
\hline \multicolumn{2}{|c|}{ Hyperuricemic group } & Before & After & $\%$ of change & $p$ value \\
\hline Uric acid & $\mathrm{mg} / \mathrm{dl}$ & $8.0 \pm 0.96$ & $5.9 \pm 1.48$ & $-26 \%$ & $p<0.01$ \\
\hline $\operatorname{CUA} \operatorname{Ccr}(R)$ & $\mathrm{mg} / \mathrm{dl}$ & $5.4 \pm 1.99$ & $9.5 \pm 2.01$ & $+75 \%$ & $p<0.01$ \\
\hline Xanthine & $\mu \mathrm{g} / \mathrm{dl}$ & $0.3 \pm 0.291$ & $0.28 \pm 0.101$ & $-6 \%$ & NS \\
\hline Hypoxanthine & $\mu \mathrm{g} / \mathrm{dl}$ & $0.47 \pm 0.223$ & $0.56 \pm 0.452$ & $+19 \%$ & NS \\
\hline Male gendr & & Before & After & $\%$ of change & $p$ value \\
\hline Uric acid & $\mathrm{mg} / \mathrm{dl}$ & $7.0 \pm 1.61$ & $5.4 \pm 1.59$ & $-23 \%$ & $p<0.01$ \\
\hline CUA/Ccr $(R)$ & $\mathrm{mg} / \mathrm{dl}$ & $5.8 \pm 2.90$ & $8.9 \pm 4.51$ & $+53 \%$ & $p=0.02$ \\
\hline Xanthine & $\mu \mathrm{g} / \mathrm{dl}$ & $0.26 \pm 0.277$ & $0.15 \pm 0.079$ & $-42 \%$ & NS \\
\hline Hypoxanthine & $\mu \mathrm{g} / \mathrm{dl}$ & $0.54 \pm 0.241$ & $0.46 \pm 0.318$ & $-14 \%$ & NS \\
\hline Female gender & & Before & After & $\%$ of change & $p$ value \\
\hline Uric acid & $\mathrm{mg} / \mathrm{dl}$ & $6.9 \pm 1.61$ & $4.9 \pm 1.83$ & $-28 \%$ & $p<0.01$ \\
\hline CUAVCcr $(R)$ & $\mathrm{mg} / \mathrm{dl}$ & $6.8 \pm 1.88$ & $11.8 \pm 0.67$ & $+73 \%$ & $p=0.02$ \\
\hline Xanthine & $\mu \mathrm{g} / \mathrm{dl}$ & $0.25 \pm 0.125$ & $0.29 \pm 0.78$ & $+16 \%$ & NS \\
\hline Hypoxanthine & $\mu \mathrm{g} / \mathrm{dl}$ & $0.49 \pm 0.250$ & $0.47 \pm 0.353$ & $-0.9 \%$ & NS \\
\hline
\end{tabular}


thought to be good candidates to treat metabolic syndromes; because basic pathophysiologic conditions of the syndromes are hyperinsulinemia and insulin resistance (24-26). Although fenofibrate belongs to fibrates with similar types of efficacies as mentioned above, it is noticeable that this drug additionally has a unique antihyperuricemic effect that other fibrates do not have (14-16). The antihyperuricemic effect of fenofibrate is reversible and is observed in healthy volunteers and hyperuricemic patients $(27,28)$. It has been already reported that fenofibrate increases the renal uric acid clearance and improve hyperuricemia (29).

In this study, we evaluated the antihyperlipidemic and antihyperuricemic effects of fenofibrate on hyperlipidemic patients. Subjects of this evaluation were selected by the usual indication of fenofibrate and not by special viewpoints of uric acid metabolism. The T-Cho and TG concentrations decreased, while HDL-C concentrations increased with statistical significance. Fenofibrate decreased the serum uric acid concentrations for both hyperuricemic and normouricemic patients at the usual clinical dose. There are three types of hyperuricemia from the viewpoints of pathogenesis; with the first type, the uric acid production increases, in the second type the urinary excretion of uric acid decreases and in the third type these two pathogeneses combine. In this study we could not evaluate the types of pathogenesis of hyperuricemia precisely, because we only obtained spot urine for analysis. The clearance ratio of uric acid to creatinin $(R)$ can be, however, used as indicator of the type of hyperuricemia. Mean $R$ is 8.68 in the first type 5.66 in the second type, and 6.42 in the third mixed type (29). The mean $R$ in this study was 6.1 in all the cases and 5.4 in the hyperuricemic group. Hence, the patients with hyperuricemia in this study were most likely to be categorized to the second type in which the urinary excretion of uric acid decreases. In Japan the incidence of this type of hyperuricemia is higher than the first type in which uric acid production increase (1). After the fenofibrate treatment mean $R$ increased to 9.9 in all the cases and 9.5 in the hyperuricemic group; this result thus indicating fenofibrate increased uric acid excretion to a much higher level than the normal one $(R=7.4)(29)$. It is consequently necessary to be careful for the uric acid level in urine to be allowed to prevent renal stone formation or renal dysfunction when fenofibrate is used to any patients.

Recently hyperuricemia has been thought to be one of the metabolic abnormalities that lead to metabolic syndrome $(30,31)$. Especially in women, there is positive correlation between serum uric acid level and leptin concentration (7). Some authors report that serum uric acid level is well correlated to prognosis of patients with type 2 diabetes and coronary heart disease (32-34). On the other hand, other authors report no correlation between serum uric acid concentration with mortality from car- diovascular disease, and another author reports that uric acid in the systemic blood flow works as an antioxidant to prevent atherosclerosis $(35,36)$. It is not clear whether decreasing the uric acid concentration improves the prognosis of patients with metabolic syndrome; as a result, whether we have to prescribe one more medicine to reduce the serum uric acid concentration in the patients with metabolic syndrome remains a difficult question. It can be, however, thought of as a favorable-side profile that the treatment of hyperlipidemia causes a mild decrease of a uric acid level. Fibrates decrease a serum TCho concentration and improve a serum lipid profile, e.g. the increase in HDL-C concentration. Fenofibrate can improve a lipid profile and uric acid abnormalities, and hence, it improves many metabolic abnormalities at once by one medicine. It is also reported that fenofibrate suppresses experimental autoimmune myocarditis in rats (37). Use of fenofibrate can be a good choice for the treatment of metabolic syndrome with hypercholesterolemia, hypertriglycemidemia and hyperuricemia.

\section{References}

(1) Akizuki S: Serum uric acid levels among thirty-four thousand people in Japan. Ann Rheum Dis, 41: 272274, 1982

(2) Kono S, Shinchi K, Imanishi K, Honjo S, and Todoroki I: Behavioural and biological correlates of serum uric acid: a study of self-defence officials in Japan. In J Epidemiol, 23: 517-522, 1994

( 3 ) Nakanishi N, Tatara K, Nakamura K, and Suzuki K: Risk factors for the incidence of hyperuricaemia: a 6-year longitudinal study of middle-aged Japanese men. In J Epidemiol, 28: 888-893, 1999

( 4 ) Takahashi S, Yamamoto T, Tsutsumi Z, Moriwaki Y, Yamakita J, and Higashino K: Close correlation between visceral fat accumulation and uric acid metabolism in healthy men. Metabolism, 46: 11621165, 1997

( 5 ) Takahashi S, Yamamoto T, Tsutsumi Z, Moriwaki $Y$, and Hada T: Increased visceral fat accumulation in patients with primary gout. Ad Exp Med Biol, 486: 131-134, 2000

(6) Bonora E, Targher G, Zenere MB, Saggiani F, Cacciatori V, Tosi F, Travia D, Zenti MG, Branzi P, Santi L, and Muggeo M: Relationship of uric acid concentration to cardiovascular risk factors in young men. Role of obesity and central fat distribution. The Verona Young Men Atherosclerosis Risk Factors Study. In J Obes Relat Metab Disord, 20: 975980, 1996

( 7 ) Matsubara M, Chiba H, Maruoka A, and Katayose $S$ : Elevated serum leptin concentrations in woman with hyperuricemia. J Atheroscler Thromb, 9: 2834,2002 
( 8 ) Bjorntorp P and Rosmond R: The metabolic syndrome - a neuroendocrine disorder? Br J Nutr, 83 (Suppl 1): S49-S57, 2000

(9) Fessel WJ: High uric acid as an indicator of cardiovascular disease. Independence from obesity. Am J Med, 68: 401-404, 1980

(10) Reunanen A, Takkunen H, Knekt P, and Aromaa A: Hyperuricemia as a risk factor for cardiovascular mortality. Acta Med Scand Suppl, 668: 49-59, 1982

(11) Tomita M, Mizuno S, Yamanaka H, Hosoda Y, Sakuma K, Matuoka Y, Odaka M, Yamaguchi M, Yosida $\mathrm{H}$, Morisawa $\mathrm{H}$, and Murayama T: Does hyperuricemia affect mortality? A prospective cohort study of Japanese male workers. J Epidemiol, 10: 403-409, 2000

(12) Takagi M: Serum uric acid as a risk factor for stroke in a fishing village of rural southern Japan. Jpn Circ J, 46: 131-136, 1982

(13) Pilger E, Pristautz H, Pfeiffer KP, and Kostner G: Risk factors for peripheral atherosclerosis. Retrospective evaluation by stepwise discriminant analysis. Arteriosclerosis, 3: 57-63, 1983

(14) Harvengt C, Heller F, and Desager JP: Hypolipidemic and hypouricemic action of fenofibrate in various types of hyperlipoproteinemias. Artery, 7: 73-82, 1980

(15) de la Serna G, and Cadarso C: Fenofibrate decreases plasma fibrinogen, improves lipid profile, and reduces uricemia. Clin Pharmacol Ther, 66: 166-172, 1999

(16) Hepburn AL, Kaye SA, and Feher MD: Fenofibrate: a new treatment for hyperuricaemia and gout? Ann Rheum Dis, 60: 984-986, 2001

(17) Yamamoto T, Moriwaki Y, Takahashi S, Tsutsumi $Z$, and Hada T: Effect of fenofibrate on plasma concentration and urinary excretion of purine bases and oxypurinol. J Rheumatol, 28: 2294-2297, 2001

(18) Zeman M, Zak A, Vecka M, Tvrzicka E, Romaniv S, and Konarkova $M$ : Treatment of hypertriglyceridemia with fenofibrate, fatty acid composition of plasma and LDL, and their relations to parameters of lipoperoxidation of LDL. Ann N Y Acad Sci, 967: 336-341, 2002

(19) Vega GL, Ma PT, Cater NB, Filipchuk N, Meguro S, Garcia-Garcia AB, and Grundy SM: Effects of adding fenofibrate $(200 \mathrm{mg} /$ day $)$ to simvastatin $(10 \mathrm{mg} /$ day) in patients with combined hyperlipidemia and metabolic syndrome. Am J Cardiol, 91: 956-960, 2003

(20) Genest J, Jr, Nguyen NH, Theroux P, Davignon J, and Cohn JS: Effect of micronized fenofibrate on plasma lipoprotein levels and hemostatic parameters of hypertriglyceridemic patients with low levels of high-density lipoprotein cholesterol in the fed and fasted state. J Cardiovasc Pharmacol, 35: 164-
172,2000

(21) le Roux CW, Murphy E, and Seed M: A retrospective assessment of the effectiveness of fenofibrate $267 \mathrm{mg}$ on high-density lipoprotein cholesterol levels in patients attending a lipid clinic. Clin Ther, 24: 1154-1160, 2002

(22) Sasaki J, Yamamoto K, and Ageta M: Effects of fenofibrate on high-density lipoprotein particle size in patients with hyperlipidemia: a randomized, double-blind, placebo-controlled, multicenter, crossover study. Clin Ther, 24: 1614-1626, 2002

(23) Despres JP: Increasing high-density lipoprotein cholesterol: an update on fenofibrate. Am J Cardiol, 88: 30N-36N, 2001

(24) Lee $\mathrm{CH}$, Olson P, and Evans RM: Minireview: lipid metabolism, metabolic diseases, and peroxisome proliferator-activated receptors. Endocrinology, 144: 2201-2207, 2003

(25) Nakamura T, Tsubono Y, Kameda-Takemura K, Funahashi T, Yamashita S, Hisamichi S, Kita T, Yamamura T, Matsuzawa Y, Group of the Research for the Association between Host $\mathrm{O}$ and Atherosclerotic Diseases under the Preventive Measure for Work-related Diseases of the Japanese Labor M: Magnitude of sustained multiple risk factors for ischemic heart disease in Japanese employees: a case-control study. Jpn Circ J, 65: 11-17, 2001

(26) Idzior-Walus B, Sieradzki J, Rostworowski W, Zdzienicka A, Kawalec E, Wojcik J, Zarnecki A, and Blane G: Effects of comicronised fenofibrate on lipid and insulin sensitivity in patients with polymetabolic syndrome X. Eur J Clin Invest, 30: 871-878, 2000

(27) Desager JP, Hulhoven R, and Harvengt C: Uricosuric effect of fenofibrate in healthy volunteers. J Clin Pharmacol, 20: 560-564, 1980

(28) Hepburn AL, Kaye SA, and Feher MD: Long-term remission from gout associated with fenofibrate therapy. Clin Rheumatol, 22: 73-76, 2003

(29) Feher MD, A. Hepburn L, Hogarth MB, Ball SG, and Kaye SA: Fenofibrate enhances urate reduction in men treated with allopurinol for hyperuricaemia and gout. Rheumatology, 42: 321-325, 2003

(30) Metabolism JSoGaN: Guideline for the management of hyperuricemia and gout. Japanese Society of Gout and NucleicAcid Metabolism, 2002

(31) Hansen OE: Hyperuricemia, gout, and atherosclerosis. Am Heart J, 72: 570-572, 1966

(32) Okada M, Ueda K, Omae T, Takeshita M, and Hirota $\mathrm{Y}$ : The relationship of serum uric acid to hypertension and ischemic heart disease in Hisayama population, Japan. J Chron Dis, 35: 173-178, 1982

(33) Taniguchi Y, Hayashi T, Tsumura K, Endo G, Fujii $\mathrm{S}$, and Okada K: Serum uric acid and the risk for hypertension and Type 2 diabetes in Japanese men: The Osaka Health Survey. J Hypertens, 9: 1209- 
1215, 2001

(34) Inoue T, Matsuoka M, Nagahama K, Iseki C, Touma T, Iseki K, Kinjo K, and Takishita S: Cardiovascular risk factors associated with pulse pressure in a screened cohort in Okinawa, Japan. Hypertens Res, 26: 153-158, 2003

(35) Sakata K, Hashimoto T, Ueshima H, Okayama A, and Group NDR: Absence of an association between serum uric acid and mortality from cardiovascular disease: NIPPON DATA 80, 1980-1994. National Integrated Projects for Prospective Observation of Non-communicable Diseases and its Trend in the Aged. Eur J Epidemiol, 17: 461-468, 2001

(36) Nieto FJ, Iribarren C, Gross MD, Comstock GW, and Cutler RG: Uric acid and serum antioxidant capacity: a reaction to atherosclerosis? Atherosclerosis, 148: 131-139, 2000

(37) Maruyama S, Kato K, Kodama M, Hirono S, Fuse K, Nakagawa O, Nakazawa M, Miida T, Yamamoto $\mathrm{T}$, Watanabe K, and Aizawa Y: Fenofibrate, a peroxisome proliferators activated receptor alpha activator, suppress experimental autoimmune myocarditis by stimulating the interleukin-10 pathway in rats. J Atheroscler Thromb, 9: 87-92, 2002 